\title{
Analgesic effect of ropivacaine with fentanyl in comparison with ropivacaine alone for continuous femoral nerve block after knee replacement arthroplasty: a prospective, randomized, double-blinded study
}

\author{
Gunn Hee Kim ${ }^{1}$, Joon Woo Lee ${ }^{2}$, Go Eun Kim', Seong Su Lee', \\ Shill Lee Son', Byung Uk Kim', Ha Na Cho', Mi Young Kwon', \\ Min Seok Koo', Ji Eun Kim ${ }^{1}$, and Mi Jung Yun ${ }^{1}$ \\ ${ }^{1}$ Department of Anesthesiology and Pain Medicine, National Medical Center, Seoul, \\ ${ }^{2}$ Department of Radiology, Seoul National University Bundang Hospital, Seongnam, \\ Korea
}

Received April 25, 2019

Revised June 19, 2019 Accepted July 15, 2019

\author{
Corresponding author \\ Mi Jung Yun, M.D., Ph.D. \\ Department of Anesthesiology and \\ Pain Medicine, National Medical \\ Center, 245 Eulji-ro, Jung-gu, Seoul \\ 04564, Korea \\ Tel: 82-2-2260-7370 \\ Fax: 82-2-2262-4766 \\ E-mail: mijung.yun@nmc.or.kr
}

Background: The analgesic effect of perineural opioid in clinical practice are still controversial. This randomized controlled trial compared analgesic effect of ropivacaine with fentanyl or ropivacaine alone for continuous femoral nerve block following unilateral total knee arthroplasty.

Methods: Fourty patients of ASA PS I or II receiving total knee arthroplasty with spinal anesthesia were enlisted and randomly allocated into two groups. Group R; bolus injection of $0.375 \%$ ropivacaine, $30 \mathrm{ml}$ and an infusion of $0.2 \%$ ropivacaine at $8 \mathrm{ml} / \mathrm{h}(\mathrm{n}=20)$. Group $\mathrm{RF}$; $0.375 \%$ ropivacaine, $29 \mathrm{ml}$ added with $50 \mu \mathrm{g}$ of fentanyl as a bolus and an infusion of $0.2 \%$ ropivacaine mixed with $1 \mu \mathrm{g} / \mathrm{ml}$ of fentanyl at $8 \mathrm{ml} / \mathrm{h}(\mathrm{n}=20)$. Local anesthetic infusion via a femoral nerve catheter was started at the end of operation and continued for 48 h. Intravenous patient-controlled analgesia with hydromorphone $(0.15 \mathrm{mg} / \mathrm{ml}, 0-1-10)$ were used for adjuvant analgesics. Position of catheter tip and contrast distribution, visual analogue scale of pain, hydromorphone consumption, side effects were recorded for $48 \mathrm{~h}$ after operation. Patient satisfaction for the pain control received were noted.

Results: The pain visual analogue scale, incidences of side effects and satisfaction were not different between the two groups ( $P>0.05$ ), but the hydromorphone usage at $48 \mathrm{~h}$ after operation were lower in the Group RF than in the Group R $(P=0.047)$.

Conclusions: The analgesic effect of ropivacaine with fentanyl for continuous femoral nerve block after knee replacement arthroplasty was not superior to that of the ropivacaine alone.

Keywords: Anesthesia and analgesia; Femoral nerve; Fentanyl; Nerve block; Ropivacaine.

\section{INTRODUCTION}

The direct analgesic activity of the opioid drugs in the central nervous system [1], and the peripheral action of them in primary afferent fibers such as suppression of either spread of action potentials or the discharge of excitatory transmitters, have been reported $[2,3]$.

From a clinical perspective, however, the effect of peri-

This is an Open Access article distributed under the terms of the Creative Commons Attribution Non-Commercial License (http://creativecommons.org/licenses/by-nc/4.0) which permits unrestricted non-commercial use, distribution, and reproduction in any medium, provided the original work is properly cited.

Copyright (c) the Korean Society of Anesthesiologists, 2020 
neural opioid are controversial. In a systematic qualitative review [4], it was reported that the buprenorphine are reassuring agent for use in extension of duration in peripheral nerve blocks of local anesthetic. Bazin et al. [5] reported that the durations of analgesia provided by a composite of lignocaine and bupivacaine, added with morphine, buprenorphine, or sufentanil, were prolonged in 80 patients after brachial plexus block for orthopedic surgery.

Kardash et al. [6], however, documented that the addition of $75 \mu \mathrm{g}$ of fentanyl to mepivacaine had no significant effects on characteristics of supraclavicular blocks. The 1 $\mu \mathrm{g} / \mathrm{kg}$ of fentanyl added to $0.75 \%$ ropivacaine did not provide significant benefit in terms of onset time, condition and duration of combined sciatic-femoral nerve block in patients receiving elective hallux valgus repair [7]. Until now, most of the clinical studies were performed using a single neural blockade. The analgesic effect of continuous perineural infusion of fentanyl added to local anesthetic has not yet been fully clarified.

We investigated the analgesic effect of ropivacaine with fentanyl in comparison with ropivacaine alone for a continuous femoral nerve blockade following total knee arthroplasty.

\section{MATERIALS AND METHODS}

This prospective, double blinded, randomized controlled trial was conducted at one hospital between October 2015 and August 2016. Institutional Review Board of our hospital approved clinical protocol and informed consent documentation (no. H-1507-056-001). Written informed consents were acquired from all the patients. This clinical investigation was registered at clinicalTrials.gov.

Patients who were planned to receive unilateral total knee replacement arthroplasty (TKA) under spinal anesthesia were evaluated for their eligibility. Adult of American Society of Anesthesiologists physical status I-II were enlisted in the study.

Patients who had contraindications to a regional anesthetic technique (e.g., local infection, sepsis, coagulation abnormality), allergy to local anesthetic or fentanyl, established neurologic deficits in the lower extremities, and inability to know the pain scales or use intravenous patient-controlled analgesia (IV-PCA) device were excluded from this study.

Patients were randomly assigned to one of two groups in a $1: 1$ ratio using a computer-generated randomization se- quence (www.randomizer.org): ropivacaine (R) or ropivacaine with fentanyl (RF) group. Anesthesiologists who did not participate in the patient care and assessment of variables generated random allocation table, enlisted participants and assigned them to interventions. Suitable subjects were allocated to treatment in order of enrollment. For the double-blind assignment, a anesthesia nurse who did not know of the study prepared treatments and ensured them with their treatment number concealed in envelop. The study drug was offered to the anesthesiologist responsible for the patient care and administering the dose.

Description of both the visual analogue scale (VAS) of pain and the use of the IV-PCA device was given to all patients before anesthesia. Patients were premedicated with 1-2 mg of IV midazolam. On entrance in the operating room, general monitoring including electrocardiography, automated oscillotonometry and pulse oximetry. Systolic and diastolic blood pressure and heart rate were recorded every 5 min during the operation. All the patients were infused with $6 \mathrm{ml} / \mathrm{kg}$ of crystalloid solution before beginning of the regional anesthesia.

The femoral nerve catheter was inserted before the induction of spinal anesthesia by one anesthesiologist experienced in these techniques who was blinded to the study.

For the femoral nerve blockade, the patient was placed in supine position and a linear 6-13 MHz probe (SonoSite M-Turbo $^{\circledR}$, SonoSite Bothell, USA) was positioned both in a transverse and longitudinal direction to the femoral crease at $2 \mathrm{~cm}$ below the inguinal crease and $2.0 \mathrm{~cm}$ lateral to the femoral artery. Once the femoral nerve was identified, the probe was positioned in a longitudinal direction to the femoral nerve. Subsequently, a 22-gauge $50 \mathrm{~mm}$ insulated needle (Stimuplex ${ }^{\circledR}$, B. Braun, Germany) was inserted using the in-plane approach near the femoral nerve. A nerve stimulator (Pajunk, Fisher \& Paykel, New Zealand) was used to prove exact location of the femoral nerve. The block needle was advanced cephalad toward the femoral nerve with an initial output of $1 \mathrm{~mA}(1 \mathrm{~Hz})$ until quadriceps femoris muscle contractions and patella snap were obtained. The position was then considered appropriate when contractions of the quadriceps and patella snap are still elicited when the voltage is reduced to an output of 0.5 $\mathrm{mA}$, but those responses are lost when the voltage is reduced to output of $0.3 \mathrm{~mA}$ as it can avoid intraneural placement. If the muscular twitch was stopped immediately following the administration of $1 \mathrm{ml}$ of the study solution, the needle location was regarded appropriate and the catheter 
was inserted. For the confirmation of catheter function, 10 $\mathrm{ml}$ of $1 \%$ lidocaine as a test dose was injected through the catheter after negative aspiration for blood in all patients and were checked for loss of cold sense in the anterior and medial thigh, as well as for motor weakness in all major muscles including quadriceps femoris.

Three milliliters of contrast medium (Omnipaque ${ }^{\mathrm{TM}} 300$ mg Inj., 10 ml, Iohexol 647 mg/ml, GE Health Care AS Korea, Korea) were administered through the catheter and the spot of the catheter tip and the diffusion of the contrast media were confirmed using a $\mathrm{C}$-arm fluoroscope.

One blind radiologist who specialized in interventional radiology randomly interpreted and qualified the radiographs of the pelvic region based on his decision. The catheter tip position were as following; type $1=$ medial, between sacroiliac (SI) joint and sacral promontory, cranial to hip joint, distal to L4-5 disc level, type 2 = lateral, lateral to SI joint, cranial to hip joint, distal to L4-5 disc level, type 3 = proximal, proximal to L4-5 disc level, type $4=$ distal, distal to hip joint, type $5=$ indetermined.

The distribution of contrast dye in the femoral sheeth were classified such as type $1=$ internal spread under the psoas muscle fascia, type 2 = external spread under the iliacus muscle fascia, type 3 = spread near the roots of the lumbar plexus, type 4 = spread along femoral nerve, type 5 = loculated at unknown anatomic location, possible far from nerve sheath.

Patients were allocated randomly to group R (bolus administration with $30 \mathrm{ml}$ of $0.375 \%$ ropivacaine and a continuous infusion with a $0.2 \%$ ropivacaine at $8 \mathrm{ml} / \mathrm{h}$ for $48 \mathrm{~h}$ after operation, $\mathrm{n}=20$ ) or group $\mathrm{RF}$ (bolus dose of $0.375 \%$ ropivacaine, $29 \mathrm{ml}$ added with $50 \mu \mathrm{g}$ [1 ml] of fentanyl, and a continuous infusion of $0.2 \%$ ropivacaine added with $1 \mu \mathrm{g} /$ $\mathrm{ml}$ of fentanyl [7,8], at $8 \mathrm{ml} / \mathrm{h}$ for $48 \mathrm{~h}$ after operation) (n = 20). The present study was performed to assess the postoperative analgesia and side effects of two infusion regimens during continuous femoral nerve block (FNB) after unilateral TKA.

Patients received spinal anesthesia with $10 \mathrm{mg}$ of bupivacaine (Marcaine ${ }^{\circledR}$, Spinal 0.5\% Heavy, $5 \mathrm{mg} / \mathrm{ml}$, AstraZeneca, Sweden). All TKA were performed by one orthopedic surgeon.

At the completion of the operation, $30 \mathrm{ml}$ of a local anesthetic solution was injected through the FNB catheter over a 10-min period depending on the group allocation. The infusion of $0.2 \%$ ropivacaine via femoral catheter was started using an infusor (AutoFuser ${ }^{\circledast}$, AceMedical Corp., Ltd.,
Korea) at a rate of $8 \mathrm{ml} / \mathrm{h}$, which was continued into the postoperative period for $48 \mathrm{~h}$. Duration for operation, volume of infused crystalloid during operation were noted.

In the postanesthetic care unit, the patients were provided with a IV-PCA device (AutoMed3200 ${ }^{\circledR}$, AceMedical Corp., Ltd.), containing hydromorphone $(0.15 \mathrm{mg} / \mathrm{ml}, 0-1$ 10). The PCA system was adjusted to a $1 \mathrm{ml}$ of bolus on demand, with a 10 min lockout interval and no background infusion of the hydromorphone solution. The patient was told to press the button if his or her pain VAS is over 30 out of 100. The cumulative bolus use of IV-PCA (ml) at 12, 24, $36,48 \mathrm{~h}$ after operation was noted as it was stored from the electronic memory of the PCA machine.

The pain intensities both at rest and with 30 degree of passive flexion of the knee were evaluated using a VAS ( $0=$ no pain and $100=$ worst pain) at $6,24,48 \mathrm{~h}$ after operation as a primary outcome measures.

The patients received intramuscular injection of $50 \mathrm{mg} /$ $\mathrm{ml}$ of ketoprofen (TOPREN INJ 50 mg ${ }^{\circledR}$, Samsung Pharm. Ind. Co., Ltd., Korea) when discontented with the IV-PCA. The salvage doses of ketoprofen at 12, 24, $48 \mathrm{~h}$ after operation, time for self-voiding from the end of operation, side effects (nausea, vomiting, dizziness, pruritus, urinary retention, urinary catheterization, chest discomfort, leakage) and patients' satisfaction score (1-5: 1, very unsatisfied; 2, unsatisfied; 3 , moderate; 4 , satisfied; 5 , very satisfied) were recorded as secondary outcome measures.

The respiratory rate was monitored by the ward nurses every $4 \mathrm{~h}$ in all patients. If the respiratory rate was less than 10 breath/min, incremental doses of IV naloxone was injected as needed and oxygen $3 \mathrm{~L} / \mathrm{min}$ was administered via a nasal cannula.

All data was gathered by a blind anesthesiologist not participated both in the anesthesia administration and patient care. The sample size was determined based on the result of a similar study [5]. The difference of mean VAS (0-100) at $10,15 \mathrm{~h}$ after operation between the control group used local anesthetic alone and the group used local anesthetic plus opioid were 15,20 , respectively. Twenty patients in each group were needed to obtain a mean VAS difference of 15 at 10, $15 \mathrm{~h}$ after the operation, accepting an alpha error of 0.05 and $90 \%$ power. Four more patients were recruited to compensate for the possible loss of follow up.

Statistical analyses were carried out using the statistical software IBM SPSS Statistic 25 (IBM Co., USA). Continuous variables were analyzed using the t-test following normalization test. Categorical variables were compared using the 
chi-square test (sex, American Society of Anesthesiologists physical status score, satisfaction score) or the Fisher's exact test (side effects). A $P$ value of $<0.05$ was regarded statistically significant.

\section{RESULTS}

At the start, 44 patients were approached, 2 of whom did not consent to be involved in the current study. The 42 patients of remainder were enrolled and randomly allocated for the study. One patient per each group was dropped from the study due to leakage of local anesthetics through the catheter. The 40 patients finished the study and their data were statistically analyzed.

The patient characteristics and duration of surgery were similar in the two groups (Table 1). There were no statistically significant differences between the two groups.

Table 1. Patient Characteristics

\begin{tabular}{lcc}
\hline \multicolumn{1}{c}{ Variable } & Group R $(\mathrm{n}=20)$ & Group RF $(\mathrm{n}=20)$ \\
\hline Age $(\mathrm{yr})$ & $69.1 \pm 7.5$ & $67.4 \pm 6.4$ \\
Sex $(\mathrm{F} / \mathrm{M})$ & $20 / 0$ & $18 / 2$ \\
Weight $(\mathrm{kg})$ & $59.3 \pm 9.8$ & $62.7 \pm 7.44$ \\
Height $(\mathrm{cm})$ & $150.5 \pm 5.6$ & $152.2 \pm 6.1$ \\
Operation time $(\mathrm{min})$ & $112.6 \pm 22.0$ & $105.7 \pm 18.3$ \\
Crystalloid $(\mathrm{ml})$ & $562.5 \pm 153.7$ & $702.5 \pm 178.2$ \\
ASA PS I/II & $9 / 11$ & $7 / 13$ \\
\hline
\end{tabular}

Values are presented as the mean \pm SD or number of patients. There was no statistically significant difference between groups in any parameter. R: ropivacaine, RF: ropivacaine + fentanyl, ASA PS: American Society of Anesthesiologist physical status.
The pain VAS were not significantly different between the two groups (Table 2). The ropivacaine with fentanyl group showed significantly lower usage of hydromorphone at $48 \mathrm{~h}$ after the operation compared to the ropivacaine alone group (Table 2). The frequencies of ketoprofen injections, time to self voiding (Table 2), side effects and satisfaction of patients (Table 3 ) were similar between the two groups.

The type of catheter tip position (1-5) (3/11/2/4/0 vs. $3 / 10 / 3 / 4 / 0$ for group $\mathrm{R}$ vs. $\mathrm{RF}, \mathrm{P}=0.970$ ) and contrast distribution (1-5) (4/4/0/5/7 vs. $3 / 3 / 1 / 3 / 10$ for group $R$ vs. RF, $\mathrm{P}=0.678$ ) were not different between the two groups.

\section{DISCUSSION}

The purpose of the current study was to examine if the additional fentanyl to ropivacaine for the continuous FNB

Table 3. Side Effects and Satisfaction Score

\begin{tabular}{lccc}
\hline \multicolumn{1}{c}{ Variable } & $\begin{array}{c}\text { Group R } \\
(\mathrm{n}=20)\end{array}$ & $\begin{array}{c}\text { Group RF } \\
(\mathrm{n}=20)\end{array}$ & P value \\
\hline Nausea & $8(40)$ & $10(50)$ & 0.751 \\
Vomiting & $3(15)$ & $4(20)$ & 1.000 \\
Dizziness & $1(5)$ & $3(15)$ & 0.605 \\
Pruritus & $1(5)$ & $1(5)$ & 0.765 \\
Urinary retention & $10(50)$ & $13(56)$ & 0.523 \\
Foley catheter & $9(45)$ & $11(55)$ & 1.000 \\
Chest discomfort & $0(0)$ & $1(5)$ & 0.231 \\
Satisfaction score $(1-5)$ & $2.9 \pm 0.8$ & $3.3 \pm 0.6$ & 0.089 \\
\hline
\end{tabular}

Values are presented as the number of patients (\%) or mean \pm SD. R: ropivacaine, RF: ropivacaine + fentanyl.

Table 2. Visual Analog Scale of Pain, Rescue Analgesics and Time to Self-voiding

\begin{tabular}{llccc}
\hline & & Group R $(\mathrm{n}=20)$ & Group RF $(\mathrm{n}=20)$ & P value \\
\hline Pain VAS (resting) & POP 6 h & $43.1 \pm 29.2$ & $43.0 \pm 20.3$ & 0.990 \\
& POP 24 h & $47.8 \pm 25.2$ & $42.7 \pm 16.4$ & 0.459 \\
Pain VAS (movement) & POP 48 h & $42.1 \pm 16.2$ & $32.6 \pm 16.4$ & 0.079 \\
& POP 6 h & $64.7 \pm 27.7$ & $64.9 \pm 23.1$ & 0.979 \\
& POP 24 h & $74.3 \pm 14.9$ & $63.3 \pm 22.9$ & 0.090 \\
Hydromorphone (mg) & POP 48 h & $65.9 \pm 18.1$ & $54.5 \pm 19.0$ & 0.068 \\
& POP 12 h & $1.29 \pm 1.08$ & $0.70 \pm 0.90$ & 0.348 \\
& POP 24 h & $2.00 \pm 1.65$ & $1.13 \pm 1.40$ & 0.264 \\
Ketoprofen (yes/no) & POP 36 h & $2.75 \pm 2.24$ & $1.40 \pm 1.62$ & 0.123 \\
& POP 48 h & $3.52 \pm 2.53$ & $1.40 \pm 1.74$ & $0.047 *$ \\
Time to self-voiding (min) & POP 12 h & $3 / 17$ & $1 / 19$ & 0.605 \\
\hline
\end{tabular}

Values are presented as the mean \pm SD or number of patients. R: ropivacaine, RF: ropivacaine + fentanyl, VAS: visual analog scale (0-100), POP: postoperative. ${ }^{*} \mathrm{P}<0.05$. 
would improve the analgesic effect of ropivacaine alone. The pain VAS were lower in the group RF than in the group $\mathrm{R}$ but there were no statistical significantes. The hydromorphone usage at $48 \mathrm{~h}$ after operation were significantly lower in the RF group in comparison with the R group.

The disagreement in the analgesic effect of peripheral opioid added to local anesthetic seems to be related with the dose, degree of approximation of peripheral nerve blocked to the spinal dorsal horn and the existence of peripheral inflammation.

The analgesic effect of epidural opioid added to local anesthetic has been proved through several clinical studies. The coadministration of fentanyl $(100 \mu \mathrm{g})$ and $1 \%$ ropivacaine expedited the beginning of sensory and motor blocks during epidural ropivacaine [9] or lidocaine [10] anesthesia without significant fentanyl-related side effects. The additional fentanyl (2 $\mu \mathrm{g} / \mathrm{ml}$ ) markedly improved the analgesic effect of a low-dose thoracic epidural infusion of bupivacaine and adrenaline [11].

The analgesic effect of epidural opioid seem to be related with the location of receptor sites in spinal cord. In rat brains, opiate receptor sites were labeled in vivo by a potent opiate antagonist and it was localized by autoradiography to make the distribution of opiate receptors visible. Silver grains indicative of the binding of opiate antagonist are separately localized in many areas of the brain with really high densities including the substantia gelatinosa of the spinal cord [12].

In separate areas of rhesus monkey spinal cord, the opiate receptor binding was measured [13]. The authors localized the receptor binding to the upper dorsal horn and reported a drop of it in this area following dorsal root transsection.

At the dorsal horn of the spinal cord, the impulse from peripheral nerve are modulated before it is transmitted centrally to evoke perception and response. Along with these mechanisms in the central nervous system, intrinsic modification of nociception can take place at the peripheral terminals of afferent nerves [3]. With the method of more peripheral administration of opioid such as peripheral axonal nerve block, intraarticular or wound infiltration, the analgesic effect of opioid added to local anesthetic are controversial.

For the interscalene brachial plexus block, the addition of 75 $\mu \mathrm{g}$ of fentanyl to $30 \mathrm{ml}$ of $1.5 \%$ lidocaine $(\mathrm{n}=41)$ speeded up the onset of sensory and motor blockade in comparison with the control group that used $30 \mathrm{ml}$ of $1.5 \%$ lidocaine plus $1.5 \mathrm{ml}$ of isotonic saline ( $\mathrm{n}=39$ ) in a randomized clinical study [14].
Twenty patients undergoing upper extremity surgery with supraclavicular blocks were prospectively randomized to receive $75 \mu \mathrm{g}$ fentanyl either added to the local anesthetic (30 ml mepivacaine $1.5 \%$ with epinephrine $5 \mu \mathrm{g} / \mathrm{ml}$ ) or given intramuscularly in a clinical study. An equivalent volume of normal saline was given in one of the two sites as a control in a double-blind fashion. The pain VAS was significantly lower only at $1 \mathrm{~h}$ after the operation in the patients who received fentanyl added to local anesthetic [6].

The effects of fentanyl added to lidocaine for axillary brachial plexus block were evaluated in 66 adult patients planned for hand and forearm surgery [15]. Patients who received mixture of lidocaine and $100 \mu \mathrm{g}$ of fentanyl for nerve block and $2 \mathrm{ml}$ of normal saline IV, had higher success rate of sensory blockade in comparison with the patients who were given lidocaine plus $2 \mathrm{ml}$ of normal saline for neural block and $2 \mathrm{ml}$ of normal saline IV or $100 \mu \mathrm{g}$ of fentanyl IV.

However, there are studies that failed to observe significant improvement of quality of analgesia when morphine was injected via interscalene approach for brachial plexus block [16]. Furthermore, there have been reports that presented the clinical efficacy of the peripheral administration of morphine such as intraarticular injection $[17,18]$. So, the degree of approximation to the spinal dorsal horn would not be the only factor for the determination of opiate analgesic effect coadministered with local anesthetics. Multiple factors including dose, route of administration and degree of inflammation may contribute to the analgesic effect of peripheral opioid.

A prospective, randomized, double-blinded study examined the analgesic effects of adding fentanyl to ropivacaine for continuous femoral nerve block using patient-controlled analgesia for $24 \mathrm{~h}$ after TKA [19]. The authors reported that the additional fentanyl did not show significant enhancement of analgesic effect after TKA. The doses of fentanyl (100 $\mu \mathrm{g}$ as a bolus and $3 \mu \mathrm{g} / \mathrm{ml}$ for infusion) and concentration of ropivacaine $(0.75 \%)$ and infusion volume $(10 \mathrm{ml} / \mathrm{h})$ were much higher than those used in our study. The patients received general anesthesia, so the baseline VAS measured was higher in comparison with that of our study. In spite of these differences, the result of the primary end point, that is VAS, was similar to that of the present study that may reflect the importance of both route of administration and degree of inflammation in analgesic effect of perineural opioid.

The administration of same drug into the various routes 
such as perineural area or nerve terminal could possibly produce different efficacy: axonal receptors might be functionally less efficient in pain modulation than receptors at the nerve terminals, especially when considering the possible influence of inflammatory condition in peripheral area, as it is generally assumed that peripheral antinociceptive effects are mainly provided by an action on primary afferent neurones [2].

During inflammation, opioid agonists could approach more esasily to neuronal opioid receptors as the perineurium is disrupted by the inflammation [20]. In sciatic nerve fibers, the axonal transport of opioid receptors was enhanced a few days after the commencement of peripheral inflammation. In the inflamed tissue, the number of opioid receptors on cutaneous nerve fibers increased but they were abolished by ligating the sciatic nerve [21]. In the present study, the results seem to be related with axonal receptors of femoral nerve and noninflammatory condition that is immediate postoperative and by the administration of preoperative antibiotics. Although it is not possible to strongly recommend the use of opioids for femoral nerve block, as the results of the present study showed that there was no difference in the pain VAS score between the two groups, it is possible to infer the mechanism of action of opioids. On the basis of the findings of the present study, opioids are thought to exert an analgesic effect when applied to the peripheral nerves that are close to the dorsal horn of the spinal cord. In addition, the analgesic effect of opioids on the peripheral nerves with no inflammatory response will be small. We believe that these suggestions imply the clinical implications for the present study.

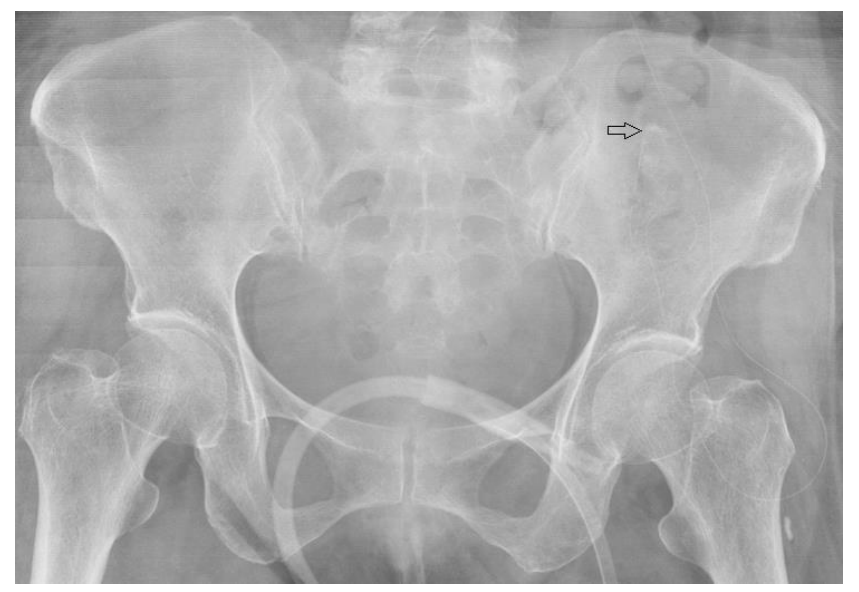

Fig. 1. The position of catheter tip (type $2=$ lateral, lateral to sacroiliac joint, cranial to hip joint, open arrow).
The position of catheter tip did not influence on the analgesic effect as there was no intergroup difference. The position of the catheter tip was of type 2 (lateral; lateral to the SI joint, cranial to the hip joint, and distal to the L4-5 disc level; Fig. 1) in 11 (55\%) patients of group R and in 10 (50\%) patients of group RF. With respect to the distribution patterns of the contrast dye, the least were of type 3 (spread near the roots of the lumbar plexus; $0,5 \%$ in both groups), and various other types were noted (Fig. 2; type 5). The Lower hydromorphone usage in the group RF than in the group R seemed to influence the similar incidences of opioid related side effects between the two groups.

The patients' satisfaction was not different between the two groups $(\mathrm{P}=0.089)$ and the reason for this result seems to be that both the VAS score and the incidence of side effects were similar between the two groups. The limitations of the FNB, that it reduces the pain mainly in the patient's anterior knee area and the high incidence of nausea in both groups (40\% in Group R and 50\% in Group RF) are thought to have contributed to the mean satisfaction score of below 4 in both groups.

Control group receiving the same dose of IV fentanyl was not included in the current study. It has been reported that the mean serum fentanyl concentration after epidural infusion of $1 \mu \mathrm{g} / \mathrm{ml}$ [8] or $2 \mu \mathrm{g} / \mathrm{ml}$ [11] were lower than the minimum effective analgesic concentration for fentanyl in serum $[11,22]$. In the present study, the degree of degeneration or preoperative pain of the knee joint to be operated, were not assessed. It was assumed that the postoperative

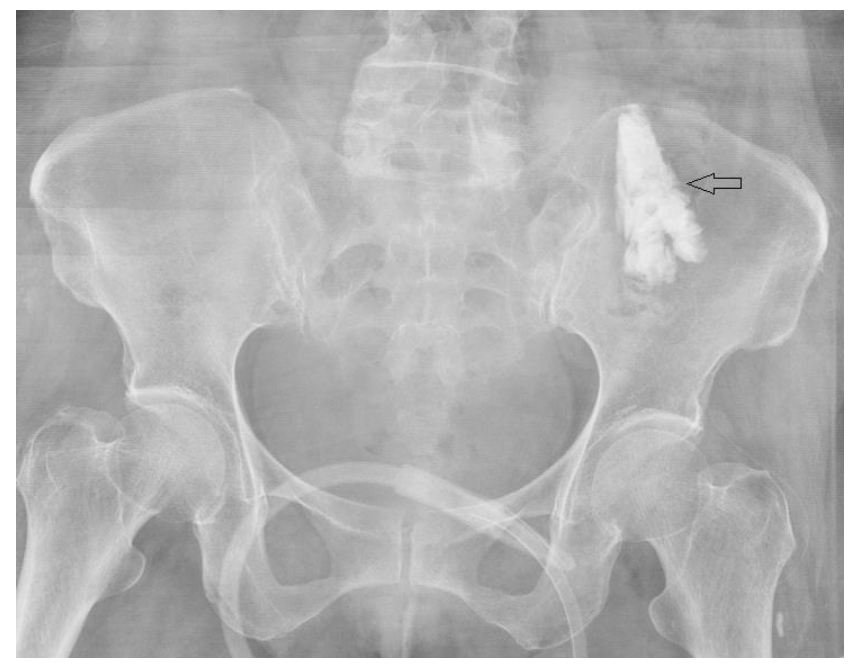

Fig. 2. The distribution of contrast dye (type $5=$ loculated at unknown anatomic location, possible far from nerve sheath, open arrow). 
pain would not much being influenced with them.

In summary, ropivacaine with fentanyl $(1 \mu \mathrm{g} / \mathrm{ml})$ for the continuous FNB did not provide significantly increased analgesic effect after TKA in comparison with the ropivacaine alone. Further studies about the analgesic effect of various doses and route of administration of opioids added to local anesthetic seem warranted.

\section{CONFLICTS OF INTEREST}

No potential conflict of interest relevant to this article was reported.

\section{AUTHOR CONTRIBUTIONS}

Conceptualization: Mi Jung Yun. Data acquisition: Go Eun Kim, Seong Su Lee, Shill Lee Son, Byung Uk Kim, Ha Na Cho. Formal analysis: Mi Jung Yun, Joon Woo Lee. Supervision: Mi Young Kwo, Min Seok Koo, Ji Eun Kim. Writing_original draft: Gunn Hee Kim, Mi Jung Yun. Writingreview \& editing: Mi Jung Yun, Gunn Hee Kim.

\section{ORCID}

Gunn Hee Kim, https://orcid.org/0000-0002-0014-8297 Joon Woo Lee, https://orcid.org/0000-0002-7106-5229 Go Eun Kim, https://orcid.org/0000-0002-7223-6317 Seong Su Lee, https://orcid.org/0000-0003-1225-4617 Shill Lee Son, https://orcid.org/0000-0001-9738-3973 Byung Uk Kim, https://orcid.org/0000-0001-9152-2709 Ha Na Cho, https://orcid.org/0000-0002-9077-9972 Mi Young Kwon, https://orcid.org/0000-0002-0667-9494 Min Seok Koo, https://orcid.org/0000-0002-2012-9616 Ji Eun Kim, https://orcid.org/0000-0002-8265-1952 Mi Jung Yun, https://orcid.org/0000-0001-5838-4893

\section{REFERENCES}

1. Millan MJ. Multiple opioid systems and pain. Pain 1986; 27: 303-47.

2. Stein C. Peripheral mechanisms of opioid analgesia. Anesth Analg 1993; 76: 182-91.

3. Stein C. The control of pain in peripheral tissue by opioids. N Engl J Med 1995; 332: 1685-90.

4. Kirksey MA, Haskins SC, Cheng J, Liu SS. Local anesthetic peripheral nerve block adjuvants for prolongation of analgesia: a systematic qualitative review. PLoS One 2015; 10: e0137312.
5. Bazin JE, Massoni C, Bruelle P, Fenies V, Groslier D, Schoeffler P. The addition of opioids to local anaesthetics in brachial plexus block: the comparative effects of morphine, buprenorphine and sufentanil. Anaesthesia 1997; 52: 858-62.

6. Kardash K, Schools A, Concepcion M. Effects of brachial plexus fentanyl on supraclavicular block. A randomized, double-blind study. Reg Anesth 1995; 20: 311-5.

7. Magistris L, Casati A, Albertin A, Deni F, Danelli G, Borghi B, et al. Combined sciatic-femoral nerve block with $0.75 \%$ ropivacaine: effects of adding a systemically inactive dose of fentanyl. Eur J Anaesthesiol 2000; 17: 348-53.

8. Lerman J, Nolan J, Eyres R, Schily M, Stoddart P, Bolton CM, et al. Efficacy, safety, and pharmacokinetics of levobupivacaine with and without fentanyl after continuous epidural infusion in children: a multicenter trial. Anesthesiology 2003; 99: 116674 .

9. Cherng CH, Yang CP, Wong CS. Epidural fentanyl speeds the onset of sensory and motor blocks during epidural ropivacaine anesthesia. Anesth Analg 2005; 101: 1834-7.

10. Cherng CH, Wong CS, Ho ST. Epidural fentanyl speeds the onset of sensory block during epidural lidocaine anesthesia. Reg Anesth Pain Med 2001; 26: 523-6.

11. Niemi G, Breivik H. Epidural fentanyl markedly improves thoracic epidural analgesia in a low-dose infusion of bupivacaine, adrenaline and fentanyl. A randomized, double-blind crossover study with and without fentanyl. Acta Anaesthesiol Scand 2001; 45: 221-32.

12. Pert CB, Kuhar MJ, Snyder SH. Opiate receptor: autoradiographic localization in rat brain. Proc Natl Acad Sci U S A 1976; 73: 3729-33.

13. Lamotte C, Pert CB, Snyder SH. Opiate receptor binding in primate spinal cord: distribution and changes after dorsal root section. Brain Res 1976; 112: 407-12.

14. Moharari R, Sadeghi J, Khajavi M, Davari M, Mojtahedzadeh M. Fentanyl supplement expedites the onset time of sensory and motor blocking in interscalene lidocaine anesthesia. Daru 2010; 18: 298-302.

15. Nishikawa K, Kanaya N, Nakayama M, Igarashi M, Tsunoda K, Namiki A. Fentanyl improves analgesia but prolongs the onset of axillary brachial plexus block by peripheral mechanism. Anesth Analg 2000; 91: 384-7.

16. Flory N, Van-Gessel E, Donald F, Hoffmeyer P, Gamulin Z. Does the addition of morphine to brachial plexus block improve analgesia after shoulder surgery? Br J Anaesth 1995; 75: 23-6.

17. Khoury GF, Chen AC, Garland DE, Stein C. Intraarticular morphine, bupivacaine, and morphine/bupivacaine for pain control after knee videoarthroscopy. Anesthesiology 1992; 77: 
263-6.

18. Stein C, Comisel K, Haimerl E, Yassouridis A, Lehrberger K, Herz A, et al. Analgesic effect of intraarticular morphine after arthroscopic knee surgery. N Engl J Med 1991; 325: 1123-6.

19. Heo BH, Lee HJ, Lee HG, Kim MY, Park KS, Choi JI, et al. Femoral nerve block for patient undergoing total knee arthroplasty: Prospective, randomized, double-blinded study evaluating analgesic effect of perineural fentanyl additive to local anesthetics. Medicine (Baltimore) 2016; 95: e4771.

20. Antonijevic I, Mousa SA, Schäfer M, Stein C. Perineurial defect and peripheral opioid analgesia in inflammation. J Neurosci 1995; 15(1 Pt 1):165-72.

21. Hassan AH, Ableitner A, Stein C, Herz A. Inflammation of the rat paw enhances axonal transport of opioid receptors in the sciatic nerve and increases their density in the inflamed tissue. Neuroscience 1993; 55: 185-95.

22. Gourlay GK, Murphy TM, Plummer JL, Kowalski SR, Cherry DA, Cousins MJ. Pharmacokinetics of fentanyl in lumbar and cervical CSF following lumbar epidural and intravenous administration. Pain 1989; 38: 253-9. 